\title{
Modification of the MACS-lift to address two technical issues with the potential to improve aesthetic results and durability: A representative case report
}

\author{
Nishioka GJ* \\ Willamette Ear Nose and Throat and Facial Plastic Surgery, Salem, Oregon
}

\begin{abstract}
The minimal access cranial suspension lift, or MACS-lift, is a short scar (incision) facelift introduced by Tonnard P. and Verpaele A. in 2007. This surgical technique uses a purse string suture to vertically elevate the submuscular aponeurotic system (SMAS) with anchoring to the temporalis muscle fascia superiorly, versus imbrication or plication techniques used with other facelift techniques. The MACS-lift is a popular procedure as it can be performed in the office surgery suite under local anesthesia. Like any surgical procedure modifications are described ${ }^{3}$ to try and improve upon the original procedure and with the MACS-lift there are 2 areas which this manuscript addresses.

The first is the infra-auricular region at the inferior attachment of the ear lobe where the MACS lift create a standing cone; and the second is the soft tissue dome contour abnormality created by the purse string suture over the parotid region. The 2 modifications presented address these 2 issues which have the potential of improving the aesthetic outcome and duration of surgical results.
\end{abstract}

\section{Case report}

The minimal access cranial suspension lift, or MACS-lift, is a short scar (incision) facelift introduced by Tonnard P. and Verpaele A. in 2007 [1-2]. This surgical technique uses a purse string suture to vertically elevate the submuscular aponeurotic system (SMAS) with anchoring to the temporalis muscle fascia superiorly, versus imbrication or plication techniques used with other facelift techniques. The MACS-lift is a popular procedure as it can be performed in the office surgery suite under local anesthesia. Like any surgical procedure modifications are described [3] to try and improve upon the original procedure and with the MACS-lift there are 2 areas which this manuscript addresses.

First, because the MACS-lift incision stops at the infra-auricular region at the inferior attachment of the ear lobe the resultant standing cone (dog ear deformity) can result in a significant vertical limb extension of the incision line for correction even with a strong vertical lift of the facial flap. Furthermore, soft tissue draping, and contouring of the neck and lower face is more limited by lack of extension of this incision posteriorly as with traditional facelift techniques. Second, the soft tissue dome (bubble) created with the purse string over the parotid region can create a surface contour abnormality that is difficult to smooth. Methods to correct the soft tissue dome have included trimming with scissors and cauterization to try and flatten the soft tissue dome to match the surface contour of the surrounding soft tissues. Two modifications are presented to address these two issues, but these modifications can also potentially improve the overall surgical outcome and durability of results.

The first modification is extension of the incision from the inferior earlobe attachment onto the postauricular surface of the pinna, continuing halfway up the concha bowl, with a superior horizontal limb extending to and stopping at the postauricular sulcus. This maneuver facilitates soft tissue draping of the cervicofacial (upper neck and lower face) flap removing the standing cone at the infra-auricular region, providing additional soft tissue flap trimming and improved in-setting, thereby improving the neck and lower face contour with a completely "hidden" incision line (Figures 1 and 2).

The second modification is placement of an additional purse string suture (parotid region) inside the first purse string suture. The first purse string suture placed covers a larger area than typically described for the MACS-lift. This second purse string suture completely flattens

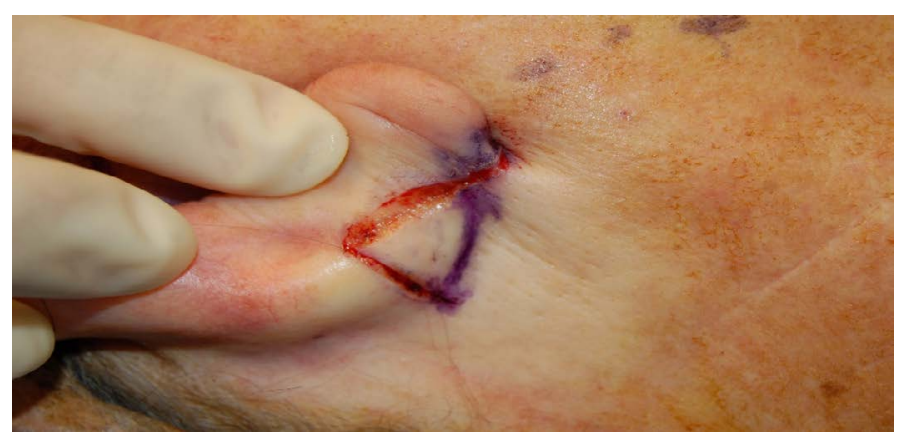

Figure 1. Right postauricular incision which extends onto the postauricular surface of the pinna (concha bowl) with the superior horizontal limb of the incision extending to the postauricular sulcus. The postauricular sulcus is marked in blue

*Correspondence to: Nishioka GJ, Willamette Ear Nose and Throat \& Facial Plastic Surgery, River Road S, Salem, Oregon, E-mail: garyn@entsalem.com

Key words: MACS-lift, modification, postauricular incision, purse string suture

Received: September 06, 2018; Accepted: September 19, 2018; Published: September 24, 2018 
Nishioka GJ (2018) Modification of the MACS-lift to address two technical issues with the potential to improve aesthetic results and durability: A representative case report

the soft tissue dome but also provides additional vertical lift, and potentially increases support and durability beyond what the first purse string suture can do alone. This author routinely places a total of 3 sutures (2-0 mersilene) in decreasing sequential concentric purse string suture loops over the parotid region. The "second purse string suture the "oblique loop" described by Tonnard and Verpaele $[1,4]$ is still made but generally slightly narrower. The need to revise previous MACS-lift has been described with methods discussed [5]. Once all purse string loops are placed a large surface area with a flat very firm tight contour is readily appreciated by inspection and palpation (Figures 3-6).

The following case report is a representative sample of patients who underwent a MACS-lift with these two modifications from 2006 to present. No complications or problems have occurred specifically related to these modifications. Nearly all patients underwent a concomitant neck procedure, open necklift or liposuction. The MACS-lift as described by the original authors generally have patients undergoing a concomitant neck procedure.

In summary, two easy to perform modifications are described for the original MACS lift which can improve the aesthetic outcome and durability without additional risk of complications above the known baseline [2].

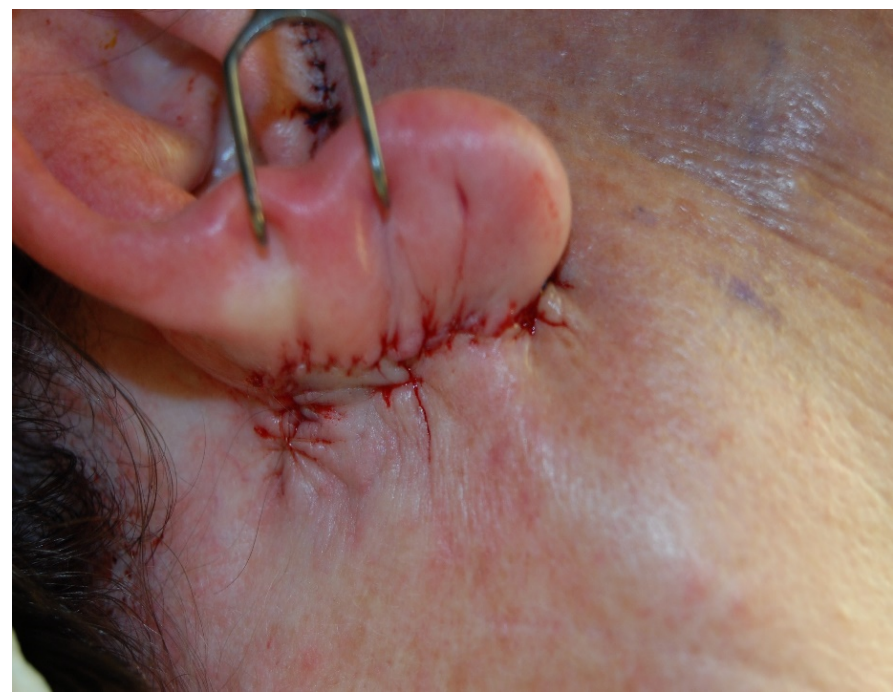

Figure 2. Completion of the closure of the postauricular extension of the incision which permits improved trimming and draping of the cervicofacial flap as well as in-setting

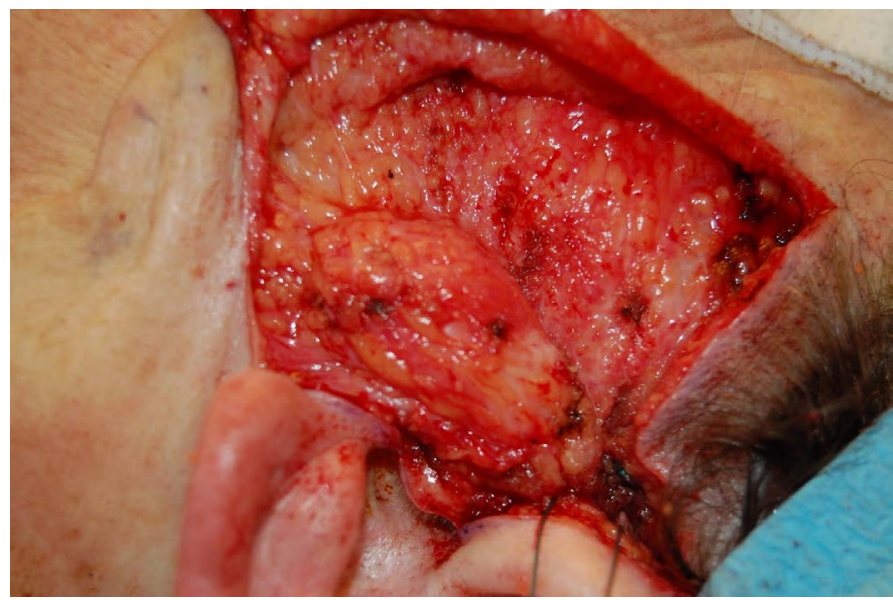

Figure 3. Bird's-eye view of the soft tissue dome created by the purse string suture over the parotid region. Patient's left side

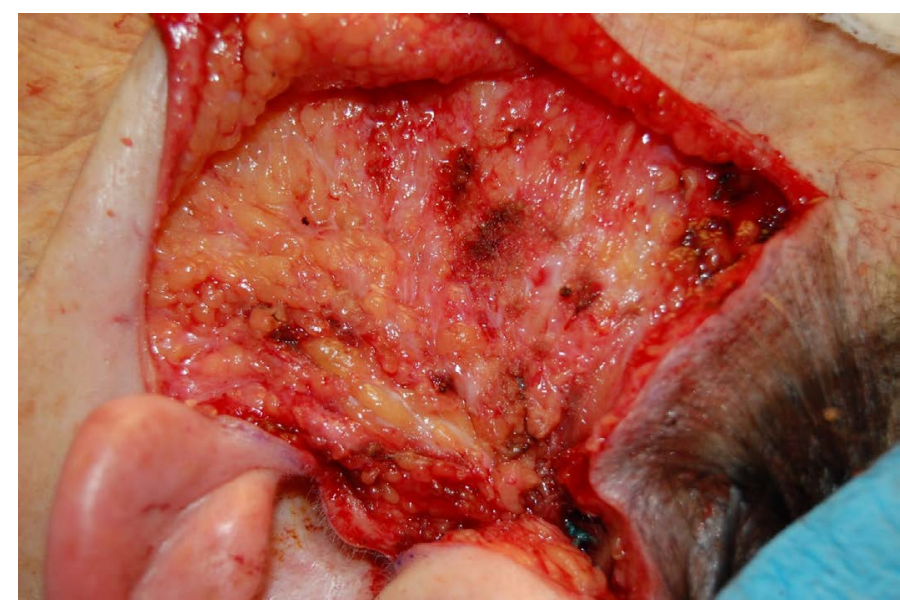

Figure 4. Bird's-eye view of the soft tissue dome following placement of the second purse string suture inside the first purse string suture. Complete flattening of the soft tissue dome seen with additional vertical lift and tightening of the region potentially providing an improved aesthetic outcome and durability. Patient's left side

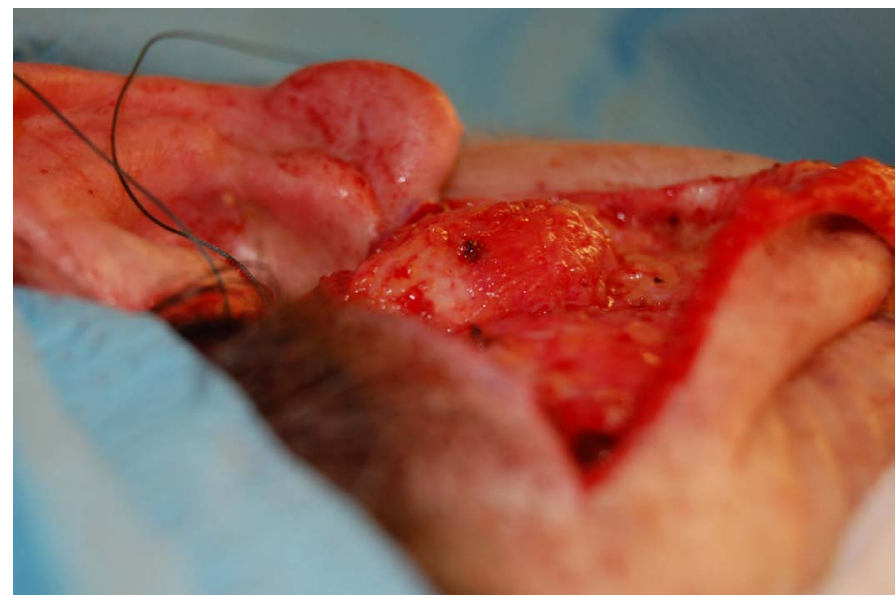

Figure 5. Surface view of the soft tissue dome created by the purse string suture over the parotid region. Patient's left side

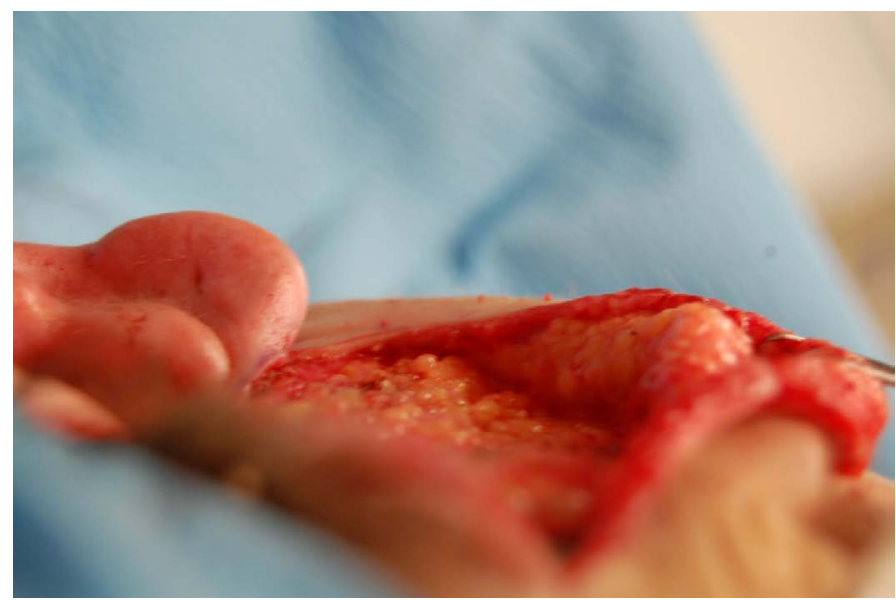

Figure 6. Surface view of the parotid region showing complete smooth flattening of the region eliminating the soft tissue done contour required deformity. Patient's left side

\section{References}

1. Tonnard P, Verpaele A (2005) 300 MACS-lift short scar rhytidectomies: analysis of results and complications. Eur J Plast Surg 28: 198-205. 
Nishioka GJ (2018) Modification of the MACS-lift to address two technical issues with the potential to improve aesthetic results and durability: A representative case report

2. Tonnard P, Verpaele A (2007) The MACS-lift short scar rhytidectomy. Aesthet Surg J27: 188-98. [Crossref]

3. Domingos DPQ, Domingos DPN (2017) A new simplified MACS lift. Plast Reconstr Surg Glob Open 5: 75-76. [Crossref]
4. Tonnard P, Verpaele A (2007) The MACS-lift short-scar rhytidectomy. Aesthetic Surg J 27: 188-198. [Crossref]

5. Corrigan B, McMillan W, Ritz M (2010) Retightening revision of a previous MACS-lift meloplasty. Aesthetic Plast Surg 34: 408. [Crossref]

Copyright: (C2018 Nishioka GJ. This is an open-access article distributed under the terms of the Creative Commons Attribution License, which permits unrestricted use, distribution, and reproduction in any medium, provided the original author and source are credited. 